\title{
Element specific investigation of ultrathin Co2MnGa/GaAs heterostructures
}

Claydon, Jill S.; Hassan, Sameh; Damsgaard, Christian Danvad; Hansen, Jørn Bindslev; Jacobsen, Claus Schelde; Xu, Yongbing B.; van der Laan, Gerrit

Published in:

Journal of Applied Physics

Link to article, DOI:

$10.1063 / 1.2712165$

Publication date:

2007

Document Version

Publisher's PDF, also known as Version of record

Link back to DTU Orbit

Citation (APA):

Claydon, J. S., Hassan, S., Damsgaard, C. D., Hansen, J. B., Jacobsen, C. S., Xu, Y. B., \& van der Laan, G. (2007). Element specific investigation of ultrathin Co2MnGa/GaAs heterostructures. Journal of Applied Physics, 101(9), 09J506. https://doi.org/10.1063/1.2712165

\section{General rights}

Copyright and moral rights for the publications made accessible in the public portal are retained by the authors and/or other copyright owners and it is a condition of accessing publications that users recognise and abide by the legal requirements associated with these rights.

- Users may download and print one copy of any publication from the public portal for the purpose of private study or research.

- You may not further distribute the material or use it for any profit-making activity or commercial gain

- You may freely distribute the URL identifying the publication in the public portal 


\title{
Element specific investigation of ultrathin $\mathrm{Co}_{2} \mathrm{MnGa} / \mathrm{GaAs}$ heterostructures
}

\author{
Jill S. Claydon ${ }^{\text {a) }}$ and Sameh Hassan \\ Electronics Department, University of York, Heslington, York YO10 5DD, United Kingdom \\ Christian D. Damsgaard \\ Department of Physics and Department of Micro and Nanotechnology, Technical University of Denmark, \\ 2800 Kgs. Lyngby, Denmark \\ Jørn Bindslev Hansen and Claus S. Jacobsen \\ Department of Physics, Technical University of Denmark, 2800 Kgs. Lyngby, Denmark \\ Yongbing B. Xu \\ Electronics Department, University of York, Heslington, York YO10 5DD, United Kingdom \\ Gerrit van der Laan \\ Daresbury Laboratory, Warrington, Cheshire WA4 4AD, United Kingdom
}

(Presented on 11 January 2007; received 30 October 2006; accepted 18 December 2006; published online 3 May 2007)

\begin{abstract}
We have used x-ray magnetic circular dichroism to study the element specific magnetic properties of ultrathin films of the Heusler alloy $\mathrm{Co}_{2} \mathrm{MnGa}$ at room temperature. Nine films were grown by molecular beam epitaxy on GaAs substrates and engineered to vary in stoichiometry as $\mathrm{Co}_{1.86} \mathrm{Mn}_{0.99} \mathrm{Ga}_{1}, \mathrm{Co}_{1.95} \mathrm{Mn}_{0.98} \mathrm{Ga}_{1}$, and $\mathrm{Co}_{1.97} \mathrm{Mn}_{0.96} \mathrm{Ga}_{1}$, with thicknesses of 5.3, 7.6, and $9.7 \mathrm{~nm}$, and were capped with $\mathrm{Al}$ to prevent oxidization. Sum rule analysis revealed magnetic moments significantly lower than the values predicted theoretically, especially in the case of the Mn total magnetic moment. The results do not support the hypothesis that a large magnetic moment is transferred from Co to $\mathrm{Mn}$, and may suggest that diffusion and reacted layers at ultrathin thicknesses can effect the establishment of a full Heusler structure. (C) 2007 American Institute of Physics. [DOI: $10.1063 / 1.2712165]$
\end{abstract}

\section{INTRODUCTION}

The fabrication of Heusler alloys, which are ferromagnetic alloys with nonferromagnetic constituents, was first reported in $1903 .{ }^{1}$ From the outset, these alloys created a great deal of interest in both experimental and theoretical fields. ${ }^{2-4}$ Recently, Heuslers have once more come to the forefront of research as their half-metallic properties ${ }^{5}$ favor both the spin polarized transport and integration with semiconductor structures required for spintronic devices. ${ }^{6-8}$

One such Heusler/semiconductor heterostructure is the combination $\mathrm{Co}_{2} \mathrm{MnGa}$ grown on $\mathrm{GaAs}(100) . \mathrm{Co}_{2} \mathrm{MnGa}$ is a full Heusler of the $L 2_{1}$ structure, ${ }^{9}$ whose combination with GaAs appears possible due to a fairly low lattice mismatch $(<2 \%)$, and has proved promising in previous investigations by our collaborators at Toshiba Europe. ${ }^{10,11}$ Despite considerable interest in integrating ultrathin Heusler films with semiconductors such as GaAs for the development of next generation spintronic devices, only a limited number of studies on the element specific magnetic moments of such structures have taken place. Grabis et al. ${ }^{12}$ found that the reduced magnetization of $\mathrm{Co}_{2} \mathrm{MnGe}$ thin films is due to a reduction of the Mn moments. Our detailed x-ray magnetic circular dichroism (XMCD) studies of ultrathin $\mathrm{Co}_{x} \mathrm{Mn}_{y} \mathrm{Ga}$ films, presented here, show that while the Mn moments are comparable to those of $\mathrm{Co}$, they are much smaller than the theoretically predicted values. Our study suggests that the

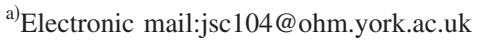

structure, composition, and, thus, the magnetic properties of the ultrathin Heusler films might be distinctly different from the bulk materials due to interface, strain, and possible interdiffusion.

\section{EXPERIMENT}

The samples were grown at the Technical University of Denmark by molecular beam epitaxy. After heating the epiready GaAs substrate to $650{ }^{\circ} \mathrm{C}$ to desorb oxygen from the surface, the substrate was allowed to cool down to $200{ }^{\circ} \mathrm{C}$ before the evaporation of the alloy films was carried out at a pressure of $5 \times 10^{-9}$ mbar. Growth was manipulated to achieve three stoichiometries: $\mathrm{Co}_{1.86} \mathrm{Mn}_{0.99} \mathrm{Ga}_{1}$, $\mathrm{Co}_{1.95} \mathrm{Mn}_{0.98} \mathrm{Ga}_{1}$, and $\mathrm{Co}_{1.97} \mathrm{Mn}_{0.96} \mathrm{Ga}_{1}$, representing $\mathrm{Co} / \mathrm{Mn}$ ratios of $1.88,1.99$, and 2.05 , respectively, and the thicknesses of 5.3, 7.6, and $9.7 \mathrm{~nm}$ achieved through the use of a shutter. Oxidization during transfer was prevented by incorporation of a 1.5-1.7 nm Al capping layer. Full details of these processes can be found in Ref. 13

$\mathrm{XMCD}$ measurements were performed at room temperature on station 1.1 of the Synchrotron Radiation Source (SRS) at Daresbury Laboratory using the portable octupole magnetic system (POMS), able to supply a field of $0.8 \mathrm{~T}$ in an arbitrary direction. The experimental setup is schematically shown in Fig. $1 .{ }^{14}$ X-ray absorption spectra (XAS) at the $\mathrm{Mn}$ and Co $L_{2,3}$ edges were obtained by recording the sample current in total electron yield (TEY) mode as a function of incident photon energy. The $I^{+}$and $I^{-}$XAS spectra, 


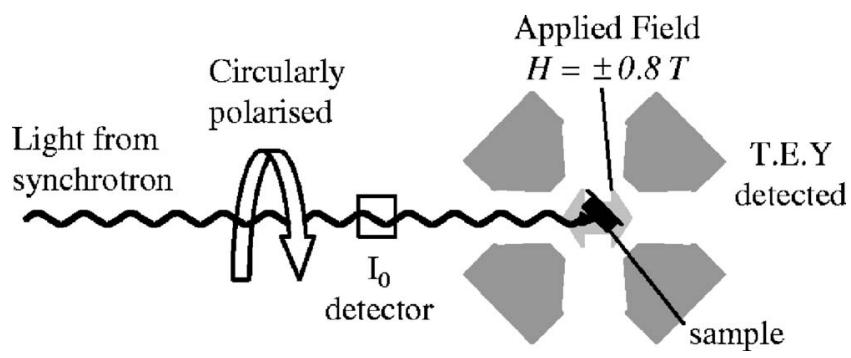

FIG. 1. Schematic plan view of the XMCD experimental setup at SRS Daresbury, utilizing the octupole magnet to apply $\pm 0.8 \mathrm{~T}$, in this case, parallel to the direction of the incident $\mathrm{x}$ rays and at $45^{\circ}$ to the sample surface.

corresponding to the photon helicity parallel and antiparallel, respectively, to the external field, were obtained by reversing the direction of the applied magnetic field at each point of the spectrum. The difference between the $I^{+}$and $I^{-}$spectra gives the XMCD spectrum.

At the $\mathrm{Mn}$ and Co $L_{2,3}$ edges, $2 p$ core electrons are excited into unoccupied $3 d$ states, allowing us to directly investigate the magnetically polarized $3 d$ band. XMCD sum rule analysis makes it possible to obtain the magnetic moments of both the Co and Mn components on a per atom basis. $^{15,16}$ Our data were analyzed by the technique of Chen et al. $^{16}$ using the standard equations; as described previously, ${ }^{17}$ the spin and orbital magnetic moments per atom are given as

$$
\begin{aligned}
& m_{\mathrm{orb}}=-4 q n_{h} / 3 r P, \\
& m_{\text {spin }}=(4 q-6 p) n_{h} / r P .
\end{aligned}
$$

The number of $3 d$ holes, $n_{h}$, was taken to be 2.2 for Co and 4.5 for Mn based on the work of Schmalhorst et al. ${ }^{18}$ and the degree of x-ray polarization, $P$, to be 0.70 . It is well known that in the case of $\mathrm{Mn}$, the sum rules require a correction, since they do not take into account the $j j$ mixing, ${ }^{19}$ i.e., the mixing of the $2 p_{3 / 2}$ and $2 p_{1 / 2}$ core levels caused by corevalence interactions. In a one-electron band structure model, the correction factor is equal to 1 , but for a completely localized system, the expected correction factor is $1.47 .{ }^{20} \mathrm{~A}$ localized Mn system would show a narrow linewidth and a distinctive multiplet structure represented by two pronounced structures in the $L_{3}$ tail and a distinctive $L_{2}$ split peak such as seen in ultrathin $\mathrm{Mn}$ films ${ }^{21}$ or the ferromagnetic semiconductor $(\mathrm{Ga}, \mathrm{Mn}) \mathrm{Ass}^{20}$ Based on the interpretation of the XAS line shapes of the Heusler alloys, which appear indicative of a fairly itinerant Mn system, the correction factor for this effect might be expected to be between 1 and 1.1 , and would thus fall within the $10 \%$ error bar of the XMCD.

\section{RESULTS AND ANALYSIS}

The XMCD of each of the nine samples were measured three times for each element (see Fig. 2) and the sum rules were applied to the resultant spectra. The average spin and orbital moments for each sample were then summed to give $m_{\text {tot }}$, a quantity directly related to the total moment per atom; these results are listed in Table I.

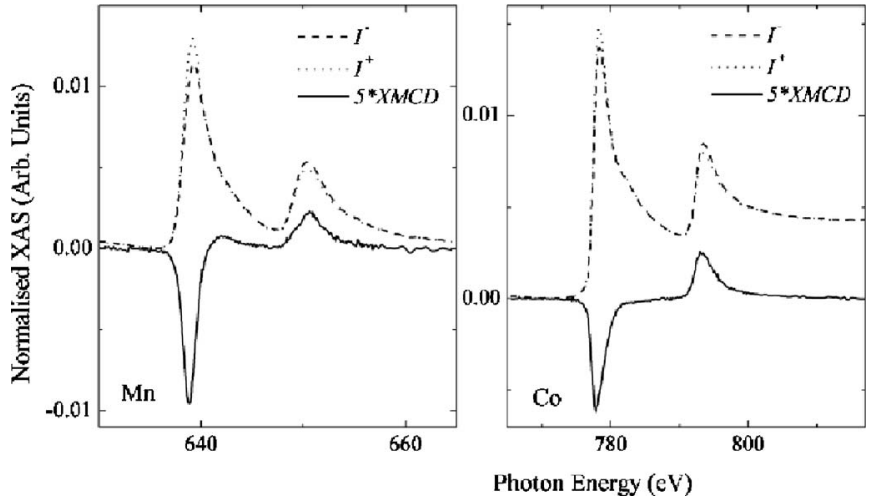

FIG. 2. Typical Mn $L_{2,3}$ (left panel) and Co $L_{2,3}$ (right panel) absorption spectra taken from $5.3 \mathrm{~nm}$ films of $\mathrm{Co}_{1.95} \mathrm{Mn}_{0.98} \mathrm{Ga}_{1}$ grown on GaAs.

Calculations at low temperature on a per atom basis have predicted the distribution of magnetism within the $\mathrm{Co}_{2} \mathrm{MnGa}$ structure to be $2.91 \mu_{B}, 0.65 \mu_{B}$, and $-0.09 \mu_{B}$ for $\mathrm{Mn}, \mathrm{Co}$, and $\mathrm{Ga}$, respectively, ${ }^{13}$ comparing well with the early low temperature experimental data on bulk $\mathrm{Co}_{2} \mathrm{MnGa}$ where the moments per atom were found to be $3.01 \mu_{B}$ and $0.52 \mu_{B}$ for Mn and $\mathrm{Co}$, respectively. Based on the results of previous work, ${ }^{10}$ the determination of the Curie temperature for a $53 \mathrm{~nm}$ film to be at $620 \mathrm{~K}$ and that of a bulk value to be at $694 \mathrm{~K}$, ${ }^{9}$ the Curie temperatures of $\mathrm{Co}_{2} \mathrm{MnGa}$ thin films are thought to be well in excess of $300 \mathrm{~K}$ when compared to $M(T)$ results for the similar alloy $\mathrm{Co}_{2} \mathrm{MnSi}^{22}$ Given this expectation, and our understanding of the behavior of full metallic films which demonstrate bulklike moments down to $\sim 6.5 \AA,,^{23}$ it is rather surprising that the measured quantities compare so differently. Furthermore, the ratio of the Mn to Co moment should not have a strong temperature dependence, and thus, it would be close to the theoretically predicted value of 5.8 if there is a large magnetic moment transfer from Co to Mn. However, if we consider the proportion of Mn to Co contributions, we see that instead of the ratio of 5.8 expected by calculation, the ratios in our experiments range from 3.1 down to 0.8 . These data would appear to suggest that our films do not exhibit the properties that one might expect of a Heusler alloy at $300 \mathrm{~K}$, since a large transfer of the magnetic moment from Co to Mn sites appears to be absent, despite the average Co moment being reduced from its bulk value of $\sim 1.7 \mu_{B}$ /atom. ${ }^{16}$ Also, with the exception of two of the thinnest films, no significant differences within the error bar are seen for the samples despite the stoichiometries being quite different.

We do not yet fully understand the reasons behind these discrepancies. Some calculations have suggested that Mn defects residing on Co sites may align themselves antiparallel with the applied field; ${ }^{13}$ however, to explain our findings, one would require an excessively high defect concentration of $38 \%$. Ex situ testing showed that the sample would be fully saturated in our measurement geometry, leaving the most likely explanation to be associated with the physical limitations of the XMCD technique.

Earlier experiments showed that the inclusion of some kind of capping layer would be necessary in order to prevent oxidization. However, in soft x-ray absorption measurements using total electron yield detection, the expected escape 
TABLE I. The sum of orbital and spin moments (with error bars) in $\mu_{B} /$ atom for the Co and Mn components as obtained from XMCD measurements on three different film structures of $\mathrm{Co}_{x} \mathrm{Mn}_{y} \mathrm{Ga}$ (indicated by the $x / y$ ratio) with three different thicknesses.

\begin{tabular}{|c|c|c|c|c|c|c|}
\hline \multirow{2}{*}{$\begin{array}{l}\text { Thickness } \\
\text { (nm) }\end{array}$} & \multicolumn{2}{|c|}{$\mathrm{Co} / \mathrm{Mn}=1.88$} & \multicolumn{2}{|c|}{$\mathrm{Co} / \mathrm{Mn}=1.99$} & \multicolumn{2}{|c|}{$\mathrm{Co} / \mathrm{Mn}=2.05$} \\
\hline & $\mathrm{Mn} m_{\mathrm{tot}}$ & $\mathrm{CO} m_{\mathrm{tot}}$ & $\mathrm{Mn} m_{\mathrm{tot}}$ & Co $m_{\text {tot }}$ & $\mathrm{Mn} m_{\mathrm{tot}}$ & Co $m_{\text {tot }}$ \\
\hline 5.3 & $\begin{array}{c}0.283 \\
\pm 0.026\end{array}$ & $\begin{array}{c}0.206 \\
\pm 0.019\end{array}$ & $\begin{array}{c}0.534 \\
\pm 0.050\end{array}$ & $\begin{array}{c}0.175 \\
\pm 0.016\end{array}$ & $\begin{array}{c}0.438 \\
\pm 0.043\end{array}$ & $\begin{array}{c}0.177 \\
\pm 0.017\end{array}$ \\
\hline 7.6 & $\begin{array}{c}0.838 \\
\pm 0.076\end{array}$ & $\begin{array}{c}0.434 \\
\pm 0.038\end{array}$ & $\begin{array}{c}0.724 \\
\pm 0.065\end{array}$ & $\begin{array}{c}0.305 \\
\pm 0.028\end{array}$ & $\begin{array}{c}0.467 \\
\pm 0.049\end{array}$ & $\begin{array}{c}0.300 \\
\pm 0.060\end{array}$ \\
\hline 9.7 & $\begin{array}{c}0.247 \\
\pm 0.025\end{array}$ & $\begin{array}{c}0.307 \\
\pm 0.008\end{array}$ & $\begin{array}{c}0.470 \\
\pm 0.051\end{array}$ & $\begin{array}{c}0.341 \\
\pm 0.036\end{array}$ & $\begin{array}{c}0.521 \\
\pm 0.065\end{array}$ & $\begin{array}{c}0.304 \\
\pm 0.027\end{array}$ \\
\hline Bulk $^{\mathrm{a}}$ & & & 3.01 & 0.52 & & \\
\hline
\end{tabular}

${ }^{\mathrm{a}}$ Reference 9 .

depth of $\sim 5 \mathrm{~nm}$ (Ref. 24) results in the capping layer impinging on the thickness which may be viewed. This suggests that the more Heusler-like results of the $5.3 \mathrm{~nm}$ thickness of the higher ratio samples, $\mathrm{Co} / \mathrm{Mn}$ are 2.0 and 2.1, describe the behavior in the upper $70 \%$ of the film thickness, implying that the alloy film does not have uniform magnetic properties. At this proximity to the interface, it is expected that such problems may be related to the diffusion and the reacted layers emanating from the interface, preventing the establishment of a true full Heusler structure.

\section{CONCLUSIONS}

We have used XMCD to measure the element specific magnetic moments of three different thicknesses of the Heusler film $\mathrm{Co}_{x} \mathrm{Mn}_{y} \mathrm{Ga}$ grown on $\mathrm{GaAs}(001)$, where the film stoichiometry was varied through $x$ and $y$ to assume the ratios of $\mathrm{Co} / \mathrm{Mn}$ of $1.88,1.99$, and 2.05 . The results did not demonstrate the expected large transfer of moment from the Co to the Mn site, but instead showed a deficit in the moment values. The thickness dependence of the results appears to point to a certain degree of magnetic nonuniformity through the alloy structure, with the Al capping layer and limited escape depth of the electron yield method preventing analysis down to greater depths. It remains a challenge to improve the growth and interface of Heusler alloy/semiconductor heterostructures for spintronics applications.

\section{ACKNOWLEDGMENTS}

This work was carried out with the aid of an EPSRC/ Daresbury Laboratory CASE studentship and the Danish Agency for Science Technology and Innovation (FNU and FTP). We would like to thank N. D. Telling and N. R. S.
Farley at SRS, Daresbury Laboratory, for their assistance with the POMS system and our collaborators S. Holmes and A. Husmann at Toshiba Europe.

${ }^{1}$ F. Heusler, Verh. Dtsch. Phys. Ges. 5, 219 (1903).

${ }^{2}$ H. H. Potter, Proc. Phys. Soc. London 41, 135 (1929).

${ }^{3}$ E. Persson, Z. Phys. 57, 115 (1929).

${ }^{4}$ A. J. Bradley and J. W. Rodgers, J. Theor. Comput. Chem. 144, 340 (1934).

${ }^{5}$ R. A. de Groot, F. M. Mueller, P. G. van Engen, and K. H. J. Buschow, Phys. Rev. Lett. 50, 2024 (1983).

${ }^{6}$ G. A. Prinz, Science 282, 1660 (1998).

${ }^{7}$ S. A. Wolf, D. D. Awschalom, R. A. Buhrman, J. M. Daughton, S. von Molnar, M. L. Roukes, A. Y. Chtchelkanova, and D. M. Treger, Science 294, 1488 (2001).

${ }^{8}$ S. Von Molnar and D. Read, Proc. IEEE 91, 715 (2003).

${ }^{9}$ P. J. Webster, J. Phys. Chem. Solids 32, 1221 (1971).

${ }^{10}$ S. N. Holmes and M. Pepper, Appl. Phys. Lett. 81, 1651 (2002).

${ }^{11}$ S. N. Holmes and M. Pepper, J. Supercond. 16, 191 (2003).

${ }^{12}$ J. Grabis, A. Bergmann, A. Nefedov, K. Westerholt, and H. Zabel, Phys. Rev. B 72, 024437 (2005).

${ }^{13}$ C. D. Damsgaard, Ph.D. thesis, Technical University of Denmark, 2006.

${ }^{14}$ N. D. Telling, N. R. S. Farley, and G. van der Laan (unpublished).

${ }^{15}$ B. T. Thole, P. Carra, F. Sette, and G. van der Laan, Phys. Rev. Lett. 68, 1943 (1992)

${ }^{16}$ C. T. Chen, et al. Phys. Rev. Lett. 75, 152 (1995).

${ }^{17}$ J. S. Claydon, Y. B. Xu, M. Tselepi, J. A. C. Bland, and G. Van der Laar, J. Appl. Phys. 95, 6543 (2004).

${ }^{18}$ J. Schmalhorst, S. Kämmerer, M. Sacher, G. Reiss, A. Hütten, and A. Scholl, Phys. Rev. B 70, 024426 (2004).

${ }^{19}$ B. T. Thole and G. van der Laan, Phys. Rev. B 38, 3158 (1988).

${ }^{20}$ K. W. Edmonds, N. R. S. Farley, T. K. Johal, G. van der Laan, R. P. Campion, B. L. Gallagher, and C. T. Foxon, Phys. Rev. B 71, 064418 (2005).

${ }^{21}$ H. A. Durr, G. van der Laan, D. Spanke, F. U. Hillebrecht, and N. B. Brookes, Phys. Rev. B 56, 8156 (1997).

${ }^{22}$ W. H. Wang, M. Przybylski, W. Kuch, L. I. Chelaru, J. Wang, Y. F. Lu, J. Barthel, and J. Kirschner, J. Magn. Magn. Mater. 286, 336-339 (2005).

${ }^{23}$ J. S. Claydon, Y. B. Xu, M. Tselepi, J. A. C. Bland, and G. van der Laan, Phys. Rev. Lett. 93, 037206 (2004).

${ }^{24}$ B. T. Thole, G. van der Laan, J. C. Fuggle, G. A. Sawatzky, R. C. Karnatak, and J. M. Esteva, Phys. Rev. B 32, 5107 (1985). 